\title{
Well-Being, Science, and Philosophy
}

\author{
Raffaele Rodogno (fillrr@cas.au.dk) \\ Prefinal Version. To appear in: Well-Being in Contemporary Society. ed. / Johnny H. Søraker; Jan-Willem \\ van der Rijt; Jelle de Boer; Pak-Hang Wong; Philip Brey. Springer, 2014. p. $39-58$ (Happiness Studies \\ Book Series).
}

\begin{abstract}
Academic research on well-being is pursued in multiple disciplines and currently exploding. Governments are also interested in the topic, as witnessed by their recent efforts to develop statistical measures of progress that include well-being indicators. Combined, this interest opens the door to the fruitful application of well-being research to society. Research on well-being, however, is not always well integrated across the disciplines that purport to study it. In particular, there is insufficient communication between the empirical study of well-being, and its normative/conceptual study as pursued in philosophy. This state of affairs is lamentable, as it robs science and public policy of the expertise of philosophers, a desirable tool when evaluating empirical claims about well-being promotion. In this article, I examine the reasons for this lack of communication. In particular, I reject the view according to which it originates in the idea that philosophers take well-being to be a single and general concept, and argue instead that it is likely to be the result of the different theoretical constraints under which philosophy and empirical science respectively operate. Finally, I show that communication can be strengthened by developing the empirical articulations of philosophical theories of well-being, and sketch how to do just that.
\end{abstract}

\section{Well-Being between philosophy, science, and public policy}

Given the central importance of well-being to each one of us (Rodogno 2010), it should not be surprising that research on well-being is pursued in multiple disciplines and currently exploding. The medical research database PubMed (2013), for example, gives more than 4 million entries on "well-being" with most of the publications concentrated in the last 30 years; and while psychology and economics have recently witnessed the birth of vigorous new fields such as hedonic psychology, the science of subjective well-being, and economics and happiness (Bruni \& Porta 2005; Bruni, Comim, Pugno 2008; Diener 1984; Easterlin 1974; Frey 2008; Frey \& Stutzer 2002; Kahneman 2000; Kahneman and Krueger 2006; 
Layard 2005; Seligman 2011; Sen 1999), in philosophy, well-being maintains its perennial centrality (Darwall 2002; Feldman 2010, Griffin 1986; Haybron 2008, Rodogno 2003; Russell 2012; Sumner 1996; Tiberius 2008). On their side, politicians have recently grown interested in the topic, as attested by the efforts made by several European governments and institutions to develop new statistical measures of progress that include well-being indicators (European Commission 2013; German Council of Economic Experts \& Conseil d'Analyse Economique 2010; Italian National Council for Economics and Labour 2013).

Combined, the academic and political interest in well-being opens the door to the fruitful application of well-being research to society. Research on well-being, however, is not always well integrated across the disciplines purporting to study it. In particular, there seems to be insufficient communication between the empirical study of well-being as pursued in economics and psychology, on the one hand, and the normative and conceptual study of well-being as pursued in philosophy, on the other. This is not to say that there are no researchers that, individually, make consistent and productive efforts at building bridges across the more conceptual and the more empirical study well-being. ${ }^{1}$ It is rather that these efforts have not yet gone far enough; they should be more widespread and systematic. Unfortunately, there still are entrenched tendencies, on the one hand, to theorize and conceptualize well-being in the absence of any concern for issues such as measurement and, on the other, to measure well-being without sufficient concern for its conceptualization. In each camp, these tendencies are sometimes accompanied by an attitude of scepticism towards the research conducted by those in the other camp. It would not be uncommon, for example, to hear complaints arising from each side concerning the very relevance or usefulness to well-being research of the work conducted by scholars on the other side.

\footnotetext{
${ }^{1}$ Notable examples are Alexandrova (2005), (2008), (2012a), (2012b); Angner (2008), (2011), (2012); Feldman (2010); Haybron (2008); Sen (1985), (1987), (1992), (1993); Tiberius (2008); Tiberius and Plakias (2010). On the more purely empirical side of well-being research, scholars such as Diener, Frey, Kahneman, and Seligman have made consistent efforts at integrating work in psychology with economics and public policy (cf. Diener and Seligman (2004), Frey (2004), Frey and Stutzer (2002), Kahneman (2000), Kahneman and Krueger (2006), Kesabir and Diener (2008)).
} 
Having established that there is at least some lack of communication in the field of wellbeing research, we should ask whether this state of affairs is less than optimal or downright pernicious. As it turns out, it is likely to be both. It is a general presumption about scientific knowledge and understanding that it tends to benefit from communication and the confrontation of ideas that it allows. There are no evident reasons to take this general presumption not to apply to the case at hand. To this extent, the current state of well-being research should count as less than optimal. Furthermore, something peculiar to well-being research makes the lack of communication particularly dangerous. By its very nature, wellbeing research has important normative practical repercussions. Any result arrived at in this field can be used more or less directly to influence clinical practices, and social and economic policies. The lack of communication may therefore ultimately have a negative impact on the well-being of those who are the object of these interventions and policies. Finally, given that public policy ultimately relies on those who provide the numbers, i.e., the economists and psychologists, the lack of communication has as its lamentable consequence to rob "science and public policy of the expertise of philosophers that could be employed to evaluate empirical claims about well-being promotion." (Alexandrova, 2012a, 3).

Having established that there is a regrettable lack of communication, we should turn to the question of its origin and, thence, its solution. According to Anna Alexandrova, at the origin of the current predicament, is a particular understanding of the concept of well-being that is widespread among philosophers. On this understanding, the concept of well-being is taken to conform to the two following assumptions (2012a, 5):

Death Bed. The concept of well-being concerns the most general evaluation of the prudential value of a person's life and not anything else. The focus of the concept of well-being is the sort of evaluation we might undertake at a person's deathbed: How has she done in life, all things considered?

Uniqueness. The substantive theory of well-being specifies the unique set of conditions that apply in all and only cases of well-being. Whenever the concept of 
well-being applies, the substantive theory of well-being is supposed to tell us what it is.

Together, these two assumptions "imply that a single substantive theory of well-being should yield the conditions under which a person's life is going well in general." (2012a, 6) Along with Alexandrova, we shall call this view invariantism about well-being. Now though invariantism is not said to be problematic in itself, it is considered to be problematic insofar as it makes philosophical analyses unusable by empirical science. That is because unlike philosophical analyses, those social and medical sciences that purportedly deal with well-being do not make general but only context-specific evaluations. Hence, while philosophical well-being is unitary and general, "a great variety of constructs of well-being are used in the various scientific projects." (Alexandrova, 2012a, 2)

To illustrate the variety of well-being concepts handled by these sciences, Alexandrova picks the case of developmental economics, gerontology, and the psychology of child wellbeing. Developmental economists, for example, typically ask how well a country is doing. The construct needed to answer this question must allow comparisons across time and nations and hence must be capable of ordering the states of well-being on some sort of scale. In his recent Human Well-Being and The Natural Environment $(2001,54)$, for example, Partha Dasgupta argues that a minimal set of indices for spanning a reasonable conception of current well-being in a poor country includes private consumption per head (encompassing food, shelter, clothing and basic legal aid), life expectancy at birth (as the best indicator of health), literacy (as a proxy for basic primary education), and civil and political liberties (as allowing people to function independently of the state and their communities).

Alexandrova's own conclusions here are to the effect that "developmental economics operates with its own construct of well-being" $(2012 \mathrm{a}, 13)$ and that this is distinct from the typical constructs philosophers use such as happiness, pleasure, satisfaction of desires, or the exercise of virtues. Yet, Alexandrova continues, "Dasgupta does not claim that his is the 
uniquely correct account of well-being, but that it is the correct one for some purposes of developmental economics." (2012a, 13) Similar conclusions are arrived at after a quick review of the prevalent conceptualizations of well-being in child psychology and gerontology.

If this is the right diagnosis, standard philosophical analysis of well-being involves invariantist features that make it unresponsive to the needs and realities of medical and social science and, hence, public policy. Making philosophical analysis relevant to policy would then involve abandoning invariantism in favour of a form of variantism. The latter is a thesis to the effect that the term well-being can invoke different kinds of evaluations and different substantive theories of well-being depending on context. "Thus in different contexts well-being may amount to the subject's hedonic profile, or their objective quality of life, or certain aspects of their health etc." (6)

Should we accept that invariantism is at the origin of the current irrelevance of the philosophy of well-being and variantism its cure? In what follows, I argue against this particular diagnosis: invariantism is not at the origin of the current predicament, for its defining assumptions actually fail to characterize philosophical theories of well-being sufficiently well. As for variantism about well-being, it is neither an option in philosophy nor the correct characterization of the empirical science of well-being. As I shall argue, we need not presuppose that scientific practice makes use of plural concepts of well-being according to context. Finally, and more positively, I sketch those moves that philosophers in collaboration with scientists ought to make in order to realize the desired rapprochement between their respective disciplines.

\section{Invariantism about Well-Being}


In order to determine whether invariantism is at the origin of the current predicament, it is important to establish that it does indeed characterize philosophical theories of well-being. In this section, I will therefore examine the invariantist credentials of some of the major theories of well-being currently on offer. In order to render this task somewhat systematic, I start from the beginning, i.e., by asking what kinds of well-being ascriptions theories of well-being are intended to systematize. As it turns out, there are two distinct though connected kinds of well-being ascriptions; theories of well-being can be viewed as primarily focusing on the one as opposed to the other.

Consider some mundane well-being ascriptions. We often ask ourselves whether certain practices or activities, e.g., working long hours, or drinking a lot of alcohol, are good for us. At least some of our well-being ascriptions, then, are attempts at identifying the kinds of things that are good for us. There are, however, other, perhaps even more mundane, kinds of well-being ascriptions. While presupposing that certain kinds of things are good for us, the function or point of these ascriptions is that of assessing how well a person's life is going (or has gone) for her. When making these ascriptions, that is, we tend to focus on the presence or absence in one's life of those things that are good for one. Importantly, the assessment is done against some substantial standards determining what amounts of what good things ought to be present or absent in one's life for one to judge correctly that the life is going or has gone well or bad for the person. The two kinds of ascriptions are distinct, for we can certainly tell whether something is good for a person without at the same time knowing how much of that good thing the person should have in order for her life to count as a good life for her.

While the first type of ascriptions described above answers the question "What kinds of things are good and bad for one?" the second answers the question "When is a life good or bad for a person?" The first question is about the idea of final value and disvalue for a person. As I shall refer to it, this is the prudential question; prudential theories offer systematized answer to this question. I shall refer to the second question as to the good life (or bad life) question; "good life" theories provide systematized answers to this question. The distinction I am making does not track a distinction between quantitative and qualitative ascriptions of well-being as much as the distinction between comparative and 
absolute ascriptions of well-being. In particular, while prudential claims enable us to make comparative ascriptions ("this option is better for me than that one" or "this one is my best option"), "good life" claims enable us to make absolute ascriptions of well-being (this option is positively good, excellent, frankly bad, would make my life not worth living etc.). ${ }^{2}$ This should suffice in guise of an introduction to this distinction, which will become clearer as we illustrate it by discussing the major theories of well-being in the two subsections below. Our main purpose there, however, will be to assess the invariantist credentials of the major theories of well-being.

\subsection{Invariantism and Prudential Theories}

Let us begin by looking at so called prudential theories of well-being. Philosophers working with this kind of theories seem to share a few general assumptions. First, at its most general or abstract level, the idea of one's well-being is an unarticulated notion: it is the idea of one's interest, advantage, private or personal good, or benefit irrespective of what anyone actually takes to give substance to this idea. Second, philosophers also generally take it that the idea of well-being is a normative (as well as a descriptive) notion. ${ }^{3}$ The idea of something being good for you, that is, involves reasons for you to desire and pursue that thing. If you fail to act in accordance with these reasons without a valid justification (as, for example, ignorance or stronger non-prudential reasons not to so act), your practical rationality is criticizable.

Third, and connected to normativity, is the idea that prudential considerations are essentially temporally extended in principle to all of one's life (and to those who believe in an afterlife, possibly also after death). Note that what is at issue here is not connected to the Death Bed. To illustrate this point, consider pension schemes. If we could be confident

\footnotetext{
${ }^{2}$ Note also that while I claim that these two types of questions are distinct, I also believe that they are in principle connected and should be answered by a unitary theory.

${ }^{3}$ Though, what type of normativity, whether, that is, it is agent-relative or agent-neutral, has recently been disputed. See Darwall (2002) for a challenge to the default view that it is agent-relative rather than agentneutral. See Rosati (2008) for a defence of the idea that well-being is agent-neutral as well as agent-relative.
} 
enough that Jim will obtain much greater goods in 10,20 , or 30 years, if only he refrained from enjoying some good now, then that is what he ought prudentially to do. Even though there are temporal considerations at stake here, and even ones that may in principle extend as far as one can expect to live (if not beyond), we are not in the business of evaluating how well Jim has done for himself. Even if, ceteris paribus, he will do better if he acts as he ought prudentially to act, Jim may all in all have a bad life. What is at issue is rather the idea that in determining what action is in one's self-interest, one cannot, on pains of irrationality, neglect that one's well-being has a temporal dimension that extends in principle to as far as one's life. If we dismiss this idea as a requirement inherent to the concept of well-being, no one could tell Jim that choosing to consume the goods immediately is imprudent or stupid.

With this common background, philosophers working with the prudential question seek to provide the necessary and sufficient conditions that determine prudential goodness. There are a number of competing views of this kind on offer. Perhaps the most influential and discussed theory in the twentieth century is the so called desire satisfaction theory, according to which the satisfaction of a person's desires is both a necessary and sufficient condition for her well-being. The notion of satisfaction involved by this type of theory is neither the affectively positive feeling of satisfaction nor the cognitive evaluation of being satisfied with something, but rather the logical sense in which desires are satisfied whenever their intentional objects obtain. Today desire theorists endorse for the most rationalized version of the theory, which we will call rational desire theories of well-being. ${ }^{4}$

Historically, one of the most noticeable alternatives to desire satisfaction theories is hedonism. On this theory any question about well-being will be directly and ultimately a question about pleasure and pain. Finally, on so called Objective List theories (Finnis, 1980),

\footnotetext{
${ }^{4}$ Under this heading, we may regroup a number of theories that are, in fact, distinct in many ways. Some of them, for example, reduce the normative notion of well-being to the non-normative notion of rational desire understood conditionally as what an agent would desire, (a) on reflection; or (b) under idealized conditions; or (c) if she were fully informed; or again as (d) what a fully informed version of herself would want for herself as she actually is. Others, however, want to avoid this reduction and characterize well-being in terms that are themselves normative as what there is reason for an agent to desire. See Sidgwick $(1907,100-112)$, Brandt (1972, 686), Rawls (1971, 408), Railton (1986), Griffin (1986) and Skorupski (1999). I do not include in this class Desire Satisfactionism theories of well-being such as Heathwood $(2011,24-25)$ insofar as they explicitly deny that rational desires determine the prudential goodness of lives.
} 
prudential goodness is identified with a plurality of substantive goods such as pleasure, knowledge, friendship, autonomy, accomplishment and even virtue.

This quick tour of the main theories populating this part of the philosophy of well-being should provide us with enough information for the purpose of assessing their alleged invariantist credentials. So far, neither one of the three theories has much to do with Death Bed because, when addressing the prudential question, prudential theories of well-being are simply not aiming at evaluating lives. As we shall see, something more, namely, an appeal to standards of some sort is required to evaluate lives in that way and the theories at hand here do not discuss or presuppose such standards.

Let us now turn to Uniqueness, whose claim is that philosophical analyses of well-being aim at finding the unique set of conditions for the correct application of the concept "wellbeing". Note that, as characterized here, the primary aim of prudential theories is not to determine when a subject is doing well or bad but rather what kinds of things are beneficial or harmful to a subject. Perhaps prudential theorists would accept claims to the effect that if the context is sufficiently different in the relevant respects, then, say, different standards would be in order to evaluate whether someone is doing well or bad. In line with Uniqueness, however, prudential theorists cannot accept that the nature of the goods that constitute an individual's well-being changes with the context. No desire theorist, for example, will accept the truth of hedonism or the objective list theory just because the context has changed. In this sense, prudential theories certainly satisfy Uniqueness. The question, to be discussed in Section 4, is, then, whether it is this feature that impedes communication between philosophy and the empirical studies well-being.

\subsection{Invariantism and "Good life" Theories}

Next we should assess the invariantist credentials of the major theories belonging to the other class. These theories systematize those mundane well-being ascriptions whose function or point is the evaluation of people's lives or aspects of their lives. The first 
important point to emphasize is that these well-being ascriptions cannot be performed in the absence of some standards, which are being met or failing to be met by an individual's life. Were you to look back on your life from your deathbed, and judge that you had had a good life you would implicitly be appealing to a standard of well-being which you must believe your life has attained. This is quite unlike the other type of well-being ascriptions. No similar standard being attained is implicated in your judgment that eating this icecream would be good for you insofar as it is pleasant or it satisfies one of your desires.

Three general remarks about the nature of the standards involved in these ascriptions are in order here, starting with the claim that the standards are taken to be different in kind. There will, hence, be standards the fulfillment (or failure to fulfill) of which will be taken to determine whether the life in question is good, the best, bad, horrendous, barely worth living, or not worth living for the person whose life it is. Some of these standards may be defined in terms of each other: hence, for example, someone may claim that a life that is not worth living is a life that fails to measure up to standards defining a life worth living, whatever these are.

Secondly, note that, conceptually, the standards that one applies in order to assess how well or bad a life is for the person whose life it is need not be understood in perfectionist terms. Perfectionism

starts from an account of the good human life, or the intrinsically desirable life. And it characterizes this life in a distinctive way. Certain properties, it says, constitute human nature or are definitive of humanity - they make humans humans. The good life, it then says, develops these properties to a high degree or realizes what is central to human nature. ${ }^{5}$

The judgments about well-being discussed so far need not be developed against the backdrop of any idea of what makes humans humans. Even if there were a correct account of human nature, there is no logical guarantee that well-being would correspond to it.

${ }^{5}$ Hurka, 1993, 3. 
Without a substantial argument to that effect, we can assume neither that the most developed (in whatever perfectionist terms) human specimen will also be best off in terms of well-being, nor that "their undeveloped rivals would not be faring better." 6

The third remark bears on the nature of the authority setting the standards. Are the standards to be determined (a) subjectively, i.e., by the subject's reflective or unreflective attitudes; (b) intersubjectively, i.e., by the community or a group of competent judges; (c) objectively, i.e., by alleged facts about human nature; or (d) differentially, in accordance with the type of standard at issue (e.g., the best life can be determined subjectively but not the standard for a life worth living)?

Perhaps the most famous historical example of a theory in this camp is Aristotle's, whose main claim was that the best life for man consists in those lifelong activities that actualize the virtues of the rational part of the soul. ${ }^{7}$ In accordance with the first remark above, note that Aristotle is not just trying to define the good life but something more ambitious, namely, the best possible human life or excellent life. In fact his theory can be considered to set objective standards in the sense that this type of life would be the best or excellent one for any human being given not only some subjective features but also objective features derived from our ergon. ${ }^{8}$

A more recent theory in this camp is L. W. Sumner's authentic happiness theory of wellbeing. This view is at bottom spelled out by two claims: (i) happiness consists in life satisfaction, and (ii) well-being is identical to happiness. ${ }^{9}$ We are told that happiness consists in, both, a cognitive and an affective aspect:

\footnotetext{
${ }^{6}$ Sumner, 1996, 24. Pace McNaughton and Rawling (2000), 157-158; 158 n. 2.

${ }^{7} \mathrm{I}$ am assuming that there are cogent interpretations of Aristotle that do not make his theory straightforwardly perfectionist in the sense described above. Russell (2012, 44-64), for example, for example, argues "that Aristotle understand eudaimonia as an agent-relative good, and understands the virtues as benefiting their possessor in an agent-relative way.

${ }^{8}$ What the latter consisted in is unfortunately a matter of exegetical dispute with important repercussions on the alleged objective nature of Aristotle's view. According to most interpreters, the ergon at issue here makes a reference to Aristotelian ideas about the metaphysical/biological essence of human nature. According to another interpretation (Adkins, 1984), however, the ergon at issue here is rather that which common practice in society assigns to each individual.

${ }^{9}$ Sumner $(1996,156-171)$ actually claims that well-being is identical to authentic happiness. This is an important point within his theory, which, however, may harmlessly be ignored here.
} 
The cognitive aspect of happiness consists in a positive evaluation of the conditions of your life, a judgement that, at least on balance, it measures up favourably against your standards or expectations. This evaluation may be global, covering all the important sectors of your life, or it may focus on one in particular (your work, say, or your family). In either case it represents an affirmation or endorsement of (some or all of) the conditions or circumstances of your life, a judgement that, on balance and taking everything into account, your life is going well for you. ... However, there is more involved in being happy than being disposed to think that your life is going (or has gone) well. The affective side of happiness consists in what we commonly call a sense of well-being: finding your life enriching or rewarding, or feeling satisfied or fulfilled by it. ${ }^{10}$

According to this theory, then, a person's well-being consists in the person's endorsement of the conditions of her life as measuring up favourably against her own standards and expectations. The person's attitudes determine the conditions under which she is doing well. Note that the standards are set by the person whose well-being is at issue who is then the ultimate authority, making this view a subjective one. Note also that the standards are not about the best possible life or the excellent life, but rather about the life one deems satisfactory or "measuring up on balance".

The question now is to understand how these particular kinds of theories square with the invariantist assumptions, starting with Death Bed. As it is clear from the last quote above, Sumner's view does not fulfill this assumption, for the evaluation/attitude which constitutes our happiness and well-being is either global or local, depending on whether it has as its focus "all the important sectors of your life... or one in particular (your work, say, or your family)." However, Death Bed is a much better fit for a theory such as Aristotle's, which expressly states that even excellent activity cannot lead to perfect happiness unless it occupied "the perfect length of a life" (NE 1177b25): a day of the best activity does not constitute happiness. (Lawrence, 1993, 18)

10 Sumner, 1996, pp-146-147 
Let us now turn to Uniqueness as stating that philosophical analysis is aimed at finding the necessary and sufficient conditions for the correct application of the concept "well-being". Sumner's life satisfaction view would indeed clearly be in agreement with this assumption. The degree to which this is problematic will once again be discussed in Section 4. As for the Aristotelian view, however, I doubt that it can be interpreted as an effort to spell out the necessary and sufficient conditions for the correct application of the concept "well-being". This would not have been standard philosophical methodology back in Aristotle's days. Also to the point is the fact that Aristotle did not think that lifelong activities that actualize the virtues of the rational part of the soul were as such sufficient for the excellent life. One also had to be sufficiently fortunate as to be placed in the right circumstances.

The picture that results from this brief review of the main types of theories of well-being tells against thinking of invariantism as what explains their lack of relevance to scientific applications, for invariantism simply fails to characterize these theories. While prudential theories fail to satisfy Death Bed, the two major "good life" theories respectively fail to satisfy one of the two invariantist assumptions.

Someone may resist this conclusion as too hasty. While theories of well-being may as suggested here primarily focus on either the prudential or the "good life" question, surely it would be wrong to see these two questions as unconnected. On pain of incoherence, the objector would continue, the prudential hedonist, for example, will not be at freedom of choosing answers to the "good life" question other than those in terms of pleasure and the absence of pain. Hence, she will have to say, for example, that the best life is the life with highest possible net surplus of pleasure over pain, the minimally good life, the life with at least some surplus of pleasure over pain, and so on. If this is granted, the objector would continue, and we accept that theories of well-being must provide answers to both kinds of questions in order to be complete, then, there will be more chances for complete theories to satisfy both invariantist assumptions. That would indeed follow from the fact that while prudential theories satisfy Uniqueness, "good life" theories seem to bring in the perspective involved by Death Bed. 
The premises of this argument do indeed seem correct. Ideally, theories of well-being should provide unified and coherent answers to both kinds of questions. The objector's conclusion, however, does not seem to follow, for it may well be quite hard for some prudential theories to specify in a way that is at all useful the standards that would make any given life best, ideal, good, worth living, bad, etc. Hedonism and desire-satisfaction theory are good cases in point here: how much surplus of pleasure over pain/satisfied over frustrated desires in a life should there be for that life to count as ideal rather than just good? Similarly, theories like Aristotle's will simply continue not to qualify as invariantist. In the light of this, while we are perhaps not in a position to exclude categorically that a given theory may qualify as invariantist, we must accept that, considered collectively, theories of well-being do not in fact display strong invariantist credentials.

\section{Against Variantism}

Even if invariantism is not at the origin of the problem, however, some may argue that variantism may be part of its solution because it is entailed by our scientific practices. If philosophy is to communicate with the sciences, it ought to endorse variantism on such pragmatic grounds. Variantism, we shall remember, is the idea that "in different contexts well-being may amount to the subject's hedonic profile, or their objective quality of life, or certain aspects of their health etc." precisely because there are several distinct concepts of well-being at play, one for each context. (Alexandrova, 2012a, 6) There is, however, one argument that tells against inferring from our well-being-ascription practices the conclusion that there are multiple, distinct concepts of well-being.

This argument is grounded in the uncotroversial idea (discussed in Section 2) that wellbeing is a normative and practical concept. Whatever conclusions any scientific study arrives at, if these conclusions are about well-being, they will be normative in the sense that they will involve reasons for action. However, if we accepted variantism about wellbeing, even if only on pragmatic grounds, the normative nature of well-being would be compromised: it would no longer be clear normatively what would follow from any claim 
about well-being. For consider now a person's well-being at one time, and allow it to differ substantively depending on context, as, for example, when the person is considered as an elderly by a gerontologist or as a citizen by an economist. Next consider that different substantive theories of well-being will, at least in principle and plausibly also in practice, have different and conflicting normative implications. Now you will have it that something is both in principle and plausibly in practice at the same time in this person's interest and not in her interest and hence that she (or those who care for her well-being) ought prudentially to pursue it and not to pursue it: admittedly, an unpalatable result. Theories of well-being must pay heed to this fact and, hence, are not at freedom to mix different kinds of substantive theories.

\section{Another look at scientific practice}

If, as argued so far, invariantism is not at the origin of the problem and variantism not part of the solution, what exactly explains the discrepancy between the science and philosophy of well-being? And how can we make research in these two fields commensurable? I contend that one simple fact is at the origin of the discrepancy. Modern empirical science has one fundamental aim that constrains its practice that philosophical practice does not share. The aim in question is measuring, and operationalization is the constraint that it imposes. Any empirical scientist who wants to gather some facts about the well-being of $X$, where $X$ is a group of individuals qua members of a developing country, or qua elderly people, or simply qua individuals, is required to have (i) an idea of what $X$ 's well-being consists in, and (ii) an idea of how to measure it. What is more, extra constraints apply in accordance to the more specific aims of the enquiry at hand, as when, for example, it is a requirement that researchers collect very large sample of data, or data that can easily be compared across time, or nations, etc. My contention is that what Alexandrova refers to as the multiplicity of well-being "constructs" results in large part from the need to measure and the process of operationalization, and the particular type of measurements that each 
study is set to achieve.

To illustrate this point, consider the following study from osteoporosis research (Lips et al., 1997 \& 1999). It appears that the aim of the psychometric tool used in this and similar studies is to measure the impact of osteoporosis and osteoporosis-related interventions on the well-being of those who suffer from this condition, with the further aim of alleviating the suffering and improving quality of life. The instrument used here for measuring suffering and quality of life within this population is a questionnaire called Qualeffo-41 (IOF) with over forty questions distributed across 5 domains: Pain (in the last week) (e.g. "How severe is your back pain at its worst?"); Physical Function (at present), in turn subdivided in Activities of Daily Living (e.g., "Do you have problems with dressing?"; Jobs Around the House (e.g. "Can you do your day-to-day shopping?"); Mobility (e.g., "Can you get up from a chair?")); Leisure and Social Activities (e.g., "How often did you visit friends or relatives during the last 3 months?"); General Health Perception (e.g., "For your age, in general, would you say your health is excellent/good/satisfactory/fair/poor."); and Mental Function (in the last week) (e.g. "Are you in good spirits most of the day?").

If the ultimate aim of studies such as this is to assess the impact on a group of individuals of a specific intervention, we should expect the measurements to be taken twice, either longitudinally (on the same population before and after the intervention), or crosssectionally (on two distinct but otherwise similar groups of patients, one which underwent the intervention while the other did not). Either way, it is clear that the researchers are only interested in the patient's well-being insofar as her osteoporosis affects her in the condition in which she has received no intervention and/or in the condition in which she has received an intervention. This clearly means that not all aspects and periods of a person's well-being are relevant. Researchers are not interested in a general assessment of the patients' well-being throughout her life (viz. Deathbed) but rather in two specific selective snapshots (or time-slices): "snapshots" because they are interested in the patient's well-being here and now (or at most the week before the measurements are being 
taken); 11 and "selective" because from a substantive point of view, the researchers are only interested in those aspects of well-being that the osteoporosis is likely to affect.

Consider now an imaginary and yet likely set of data collected during a longitudinal study using the Qualeffo-41. Suppose that it is true of a significant portion of the patients to which the questionnaire is administered that during the intervention period their spouse passed away and, as a result, the post-intervention set of measurements showed a significant decrease in their mental health. The researchers would want to dismiss this part of the data as a confounding factor to be explained away, for the decrease in mental health would not be caused by the condition or the intervention. If they could sharpen their psychometric tools so as to avoid this type of confound, they would certainly do it. Given their purposes, this would be an entirely legitimate move. Yet, no one should take this as showing that the death of one's spouse is not a legitimate cause of ill-being for osteoporosis patients, nor that the "construct" that underlies this particular psychometric tool involves a new context-specific concept of well-being in which spousal relations are not causes of well-being. All we should be inclined to infer here is that, given their specific aims, researchers are only interested in certain causes of well-being and not others.

It is worth dwelling on this point with the help of two more examples. Consider cases unlike the one above in which questionnaires cannot be directly administered to the subjects because they cannot answer as, perhaps, when we are trying to measure the wellbeing of young children with various handicaps. With what tools are scientists going to assess the dimension referred to as "suffering" for example? Sure enough, they will choose indicators that are more objective than asking patients directly about their pain levels. They will most probably ask parents about their child's pain behavior, and perhaps observe the children and infer from their impaired physical functioning the possibility of suffering. It may well-be that suffering plays a less prominent role in the psychometric tool of this latter group of scientists. Surely, however, no one would be in a position to infer from this

\footnotetext{
11 This is true of all questions, except Question 32, which asks the patient to rate her overall quality of life compared with 10 years ago. If this question is asked before and after the intervention, this is of course another way of validating the impact of the intervention on the person's current well-being.
} 
that these scientists' well-being construct takes subjective sides of well-being including suffering to be prudentially less important for this group of children than, for example, for osteoporosis patients. Nor could we infer that these scientists' conception of well-being is more objectivistic, not even just for the purposes of the study at hand.

The same point can be extended even further, to other disciplines. Consider Partha Dasgupta's minimal set of indices, which, as you will remember, includes private consumption per head, life expectancy at birth, literacy, and civil and political liberties. Why think that this is one among many plausible accounts of well-being distinct from either happiness or pleasure or satisfaction of desires or an Aristotelian exercise of virtues? The most direct explanation for Dasgupta's choice is that it was in large part imposed on him by operationalization constraints given the aims of his study. Even if Dasgupta had been a desire satisfaction theorist or a hedonist, he would have not been at freedom of choosing questionnaires and other more subjective measurement in order to compare the progress in well-being of billions of people (entire developing countries), as that would have been utterly impracticable.

If this line of argument is correct, then, the original description of the discrepancy between science and philosophy is misguided. A quick look at this part of the scientific practice does not suggest, let alone grant the inference that what is at issue here is a plurality of notions, or accounts of well-being, each with its own substantive theory. A closer description of this practice rather suggests that scientists intend to measure different aspects of one thing, i.e., well-being, or aspects of it as it pertains to this or that group of individuals (osteoporosis patients, citizens of developing countries, children, etc.), or again, the well-being of certain groups at specific times, etc. Whatever the actual conception of well-being that each individual scientist of well-being implicitly holds, I contend that the above is the picture that is most reasonable to extrapolate from the relevant scientific practice.

In order to be more specific about this picture and its differences with Alexandrova's, the following should be helpful. As proposed here, the scientific context with its general operationalization requirement, and the specific context provided by the particular 
scientific question at issue (e.g., the effect on the well-being of osteoporosis patients of certain clinical interventions) have the function of narrowing down the focus of well-being evaluations to those aspects of well-being made relevant by the specific scientific question that are also appropriately measurable. To say that these evaluations focus only on certain aspects, is to say that they are partial evaluations of well-being, not that those who use them are working with an entirely different concept of well-being from those who are interested in well-being in other contexts. To illustrate, if I am interested in evaluations of well-being that take into account levels of pain in one context but not in another, it is because I am focusing on different aspects of well-being (in each context) and not on different concepts of well-being (according to context).

Another fact that emerges from looking at the scientific practice is that, while the measuring instruments are often scrupulously described (due to a concern with replication), it is often less clear why the alleged aspects of well-being up for measurement should in fact be considered as aspects of well-being, and how the data collected precisely connects to these aspects of well-being. It is here, I shall think, that philosophers should be more active than they have been in providing the "framework for understanding how the great variety of well-being constructs does or does not fit together". (Alexandrova, 2012a, 25) In what remains of this section, I shall sketch one way in which philosophical thinking and empirical science can work together to bridge the gap between their respective fields.

In light of our discussion in this section, we should now see the discrepancy at issue between science and philosophy not as that between variantist and invariantist approaches, but as that between practices regulated by different aims. While one practice generates countless empirical measurements of alleged (aspects of) well-being with no clear connections to conceptions of well-being, the other generates abstract conceptions of well-being with no empirical articulation. How can these two practices come together?

Consider the osteoporosis study once again. What is the philosopher to do with the five domains (pain, physical function, leisure and social contact, general health perception, and mental function) that appear in the Qualeffo-41? In line with the discussion in Section 2, the 
first thing that we should be clear about is whether this instrument is itself connected to prudential theories rather than good life theories or vice versa. It is quite clear that the questionnaire is not feeding directly into a good life or bad life theory, for it does not itself presuppose or afford any specific standard of evaluation against which the data that it delivers may be evaluated. We are not said anything about how to evaluate the situation of someone who scores very poorly on this questionnaires (i.e., someone who feels extreme pain, has close to no physical function, and cannot engage in any leisure or social activity). Some of us may be inclined to think that this person has at this point a very bad life and perhaps one that is not worth living. But this type of good/bad life judgements is not part of the picture here, for the study in question is aimed at evaluating only those aspects of wellbeing that are likely to be affected by osteoporosis, not all the aspects of well-being that may affect how well a life goes.

If the scientists intend to measure the impact of osteoporosis or osteoporosis-interventions on patients' well-being, as they avowedly are, they must be taking themselves to be measuring more or less directly some of the things that are likely to make lives better or worse for their subjects. This places a study such as this in direct connection to what we called prudential theories, which, as you remember, attempt to determine what kinds of things are good and bad for individuals. The scientists involved in this study must therefore assume that the five domains tapped into by the Qualeffo- 41 are measuring elements that are either intrinsic or instrumental to well-being in some way or other. Yet, while it must be assumed that, say, visiting friends is intrinsically or instrumentally good for the patients, we do not know, from a study such as this, which one of these it is and why it would be.

Finding answers to questions such as these has traditionally been the task of philosophers, and an important task at that. We could, for example, easily imagine how different kinds of intervention may differentially affect the five dimensions of the Qualeffo- 41 . What if one intervention is better than another at lowering pain levels but not as good at facilitating leisure and social activity: which intervention is better for osteoporosis patients? At this juncture, philosophers should intervene and determine what parts of the data could be justified in terms of their favourite account of well-being and what parts couldn't. 
One could, for example, explain what's being measured in hedonistic terms: pain would of course be intrinsically bad; leisure and social activity would be relevant insofar as they were direct sources of pleasure and their absence a missed opportunity for pleasure; good health would be considered as instrumentally good insofar as it is a precondition for many pleasant activities and lack of health may be instrumentally bad as well as a source of pain (or perhaps as intrinsically good and bad if its presence somehow involves pleasure and its absence pain); finally, mobility would in large part be instrumental to activities that are likely to generate pleasure.

Similar stories could of course be recounted by desire satisfaction theorists as well as Objective List theorists. While, the hedonist explains and justifies each one of these domains in terms of pleasure and the absence of pain, the desire satisfaction theorist will have to explain and justify them in terms of rational desire satisfaction or frustration, and the objective list theorist in terms of those intrinsic goods and evils that appear on her list. If it could be shown for some element that it did not correlate with pleasure or pain, or with rational desire, or with the goods on the objective list, philosophers would have to say that the Qualeffo-41 should be modified accordingly. Similarly, if philosophers thought in accordance to their theory that there were important sources of well-being that have not been given their due in the Qualeffo-41 in its current form, then, once again, the instrument should be modified.

Unfortunately, however, in their current state of development, philosophical theories of well-being are too abstract to accomplish the task just described; they simply lack sufficient empirical articulation. ${ }^{12}$ In order to employ hedonism in the way suggested above, for example, we would have to know whether the activities in question are causes of pleasure. This is an empirical question in principle susceptible of receiving general answers of the kind "For most people engaging in activity of kind $x$ is more pleasant than failing to engage in it". This further empirical articulation of a philosophical position is necessary in order to

${ }^{12}$ Here too there are noticeable exceptions. See Railton (unpublished); Sumner (1996, Ch.6); Tiberius \& Plakias (2010) 
bridge the gap between the philosophy and the science of well-being.

This, however, is not an insurmountable problem, for there is already some evidence that philosophical theories can use and more evidence can certainly be produced. Hence, for example, hedonists can appeal to evidence that correlates participation in social activities, and leisure and recreation, with higher levels of positive affect, which could arguably be understood as a hedonistic measure (Diener and Seligman, 2002; Argyle 2001). Though this and similar findings suggest, rather than definitively establish, causality (there is the possibility that higher level of positive affect be explained by personality traits such as being extraverted, see Diener et al. 1992), the point here is that it is not in principle impossible for philosophical theories to become sufficiently empirically articulated to provide the normative framework that is expected from them.

Perhaps, in the process, we may well find out that empirical articulation is more troublesome for some philosophical theories rather than others. Rational desire theories quickly come to mind here. ${ }^{13}$ What kinds of things is it in fact rational for most people to desire? With its mixture of affect measures and life satisfaction measures, it may be argued that the subjective well-being construct (Diener, 1982) would offer evidence that could eventually put some substantive meat on the bones of rational desire theories. The levels of happiness or subjective well-being that subjects tend to experience in connection with this or that activity or domain of their lives would, on this view, provide defeasible information about their rational desires. Though this view cannot be further unpacked here, the idea behind it is not unknown to current philosophical discussion (Railton, unpublished; Tiberius \& Plakias, 2010). The important point here is once again that there may be ways of bridging the gap between abstract philosophical theories and empirical work on wellbeing, on condition that our theories preliminarily receive the kind of empirical articulation sketched here.

As this process of articulation is carried out, it may turn out that certain philosophical

${ }^{13}$ Fore relevant references see footnote 4 . 
theories are more directly and/or more fully operationalizable than others, given the current instruments available. Philosophers should then ponder whether to rest content with taking whatever evidence their theory can justify given the current tools and the current state of empirical research on well-being (e.g. subjective well-being constructs and the like), or whether, in collaboration with the relevant scientists, it would be wise and feasible to develop new and more appropriate instruments. Even after such developments, some theories may just turn out to be harder to articulate than others, making them blunter tools for the evaluation of empirical claims about well-being. Some may suggest that these theories should then be put aside in favour of their better performing rivals. For, if they are ethical theories, then, they must be practical in the sense of allowing for the evaluation of action: relative incapacity in this respect should partly disqualify them. Others, however, may want to resist this move by pointing out that this would be the wrong kind of reason to dismiss a theory, if that theory in fact captures the core of the concept of well-being better than its more empirically versatile rival. But this is a topic for another day.

\section{Conclusion}

While denying that the current lack of communication between the science and philosophy of well-being is to be blamed on invariantism, I have argued that it results from the fact that different disciplines have different aims and operate under different requirements. In particular, while empirical disciplines operate under the constraints imposed by operationalization, philosophy does not. As a result of such constraints the former generates empirical measurements of alleged aspects of well-being that often lack a clear conceptual connections to well-being, while the latter generates abstract conceptions of well-being with no empirical articulation. This, however, is not to say that a rapprochement between the two camps is impossible. The gap may be bridged by articulating the empirical consequences of theories of well-being so as to enable them to make sense of and, if necessary, correct and develop the tools currently employed to measure well-being. This process of articulation requires an increased level of co-operation between philosophy and 
the relevant empirical sciences.

\section{References}

Adkins, A. W. H. 1984. The Connection between Aristotle's Ethics and Politics. Political Theory. 12.1

Alexandrova, A. 2005. Subjective Well-Being and Kahneman's Objective Happiness. Journal of Happiness Studies 6.3: 301-324

Alexandrova, A. 2008. First-Person reports and the measurement of happiness. Philosophical Psychology, 21: 571-583

Alexandrova, A. 2012a. Values and the Science of Well-Being: A Recipe for Mixing. In the Oxford Handbook for Philosophy of Social Science, ed. H Kincaid.

https://docs.google.com/file/d/0B9W2e1dn9F00VNnNktoaS1RU3M/edit?pli=1 Retrieved on 8 February 2013.

Alexandrova, A. 2012b. Well-Being as an Object of Science. Philosophy of Science, 79.5

Alexandrova, A. Online First. Doing Well in the Circumstances. Journal of Moral Philosophy

Angner, E. 2008. The Philosophical Foundations of Subjective Measures of Well-Being. In Bruni, L., Comim F., Pugno M. (eds.) Capabilities and Happiness. Oxford: Oxford University Press: 286-298

Angner, E. 2011. Are Subjective Measures of Well-Being 'Direct'? Australasian Journal of Philosophy 89(1): $115-130$

Angner, E. 2012. Subjective Well-Being: When, and Why it Matters. (MS) Available at SSRN:

http://ssrn.com/abstract=2157140 or http://dx.doi.org/10.2139/ssrn.2157140

Argyle, M. 2001. The Psychology of Happiness. New York : Taylor \& Francis

Aristotle 1984. Nicomachean Ethics. Trans. W.D. Ross. In Barnes J. (ed.), The Complete Works of Aristotle, 2 vols. Princeton: Princeton University Press.

Brandt, R. 1972. Rationality, Egoism, and Morality." The Journal of Philosophy 69 
Bruni L, Porta PL (eds) (2005) Economics and Happiness. Framing the Analysis. Oxford University Press, Oxford

Bruni L, Comim F, Pugno M (eds) (2008) Capabilities and Happiness. Oxford University Press, Oxford

Brülde, B. 2007. Happiness and the good life: Introduction and conceptual framework. Journal of Happiness Studies, 8.1

Darwall, S. 2002. Welfare and Rational Care. Princeton: Princeton University Press

Dasgupta, P. 2001. Human Well-Being and The Natural Environment. Oxford:Oxford University Press

Diener, E. 1984. Subjective well-being. Psychological Bulletin 95:542-575

Diener, E., Sandvik, E., Pavot, W., \& Fujita, F. (1992). Extraversion and Subjective Well-being in a U.S. national probability sample. Journal of Research in Personality, 26, 205-215.

Diener, E., \& Seligman, M.E.P. (2002). Very Happy People. Psychological Science, 13 (1), 81-84

Easterlin RA (1974) Does Economic Growth Improve the Human Lot? Some Empirical

Evidence. In: David PA, Reder MW (eds) Nations and Households in Economic Growth: Essays in Honour of Moses Abramowitz. Academic Press, New York and London

European Commission 2013. http://www.beyond-gdp.eu/ Accessed 20 May 2013

Feldman F (2010) What is This Thing Called Happiness? Oxford University Press, Oxford

Finnis, J. 1980. Natural Law and Natural Rights. Oxford: Clarendon Press

Frey BS (2008) Happiness: A Revolution in Economics. MIT Press, Cambridge

Frey BS, Stutzer A (2002) Happiness and Economics: How the Economy and Institutions Affect Well-Being. Princeton University Press, Princeton and Oxford

German Council of Economic Experts \& Conseil d' Analyse Economique 2010. Monitoring economic performance, quality of life and sustainability. http://www.sachverstaendigenratwirtschaft.de/fileadmin/dateiablage/Expertisen/2010/ex10_en.pdf Accessed 20 May 2013

Griffin, J. (1986) Well-being: Its Meaning, Measurement and Moral Importance. Oxford: Oxford Clarendon Press

Haybron, D.M. 2008. The Pursuit of Unhappiness: The Elusive Psychology of Well-Being. Oxford: Oxford University

Heathwood, C. 2011. Preferentism and Self-Sacrifice. Pacific Philosophical Quarterly 92 
IOF (International Osteoporosis Foundation). 1997. Quality of Life Questionnaire: Qualeffo-41. http://www.iofbonehealth.org/sites/default/files/PDFs/Quality\%20of\%20Life\%20Questionnaires /Qualeffo41_english_questionnaire.pdf

Hurka, T. 1993. Perfectionism. New York: Oxford University Press

Italian National Council for Economics and Labour (2013) First Repot on Equitable and Sustainable Well-Being.

http://www.misuredelbenessere.it/fileadmin/upload/Report_on_Equitable_and_Sustainable_W ell-being_-_11_Mar_2013_-_Summary.pdf Accessed 20 May 2013

Kahneman D (2000) Experienced Utility and Objective Happiness: A Moment Based Approach. In: Kahneman D, Tversky A (eds) Choices, Values, and Frames. Cambridge University Press, New York

Kahneman D, Krueger AB (2006) Developments in the Measurement of Subjective Well-Being. Journal of Economic Perspectives 20(1): 3-24

Layard R (2005) Happiness: Lessons from a New Science. Penguin, New York

Lawrence, G., 1993. Aristotle and the Ideal Life. Philosophical Reivew. 102.1

Lips, P., Cooper, C., Agnusdei D., Caulin F., Egger P., Johnell O., et al. 1997. Quality of life as outcome in the treatment of osteoporosis; the development of a questionnaire for quality of life by the European Foundation for Osteoporosis. Osteoporos International 7:36-8.

Lips,P. and C. Cooper, D. Agnusdei, F. Caulin, P. Egger, O. Johnell, J. A. Kanis, S. Kellingray, A. Leplege, U. A. Liberman, E. McCloskey, H. Minne, J. Reeve, J.-Y. Reginster, M. Scholz, C. Todd, M. C. de Vernejoul and I. Wiklund for the Working Party for Quality of Life of the European Foundation for Osteoporosis. 1999. Quality of Life in Patients with Vertebral Fractures: Validation of the Quality of Life Questionnaire of the European Foundation for Osteoporosis (QUALEFFO). Osteoporos International 10:150-160.

McNaughton, D., Rawling, P. 2001. Achievement, welfare, and consequentialism. Analysis, 61.2

PubMed 2013. http://www.ncbi.nlm.nih.gov/pubmed/?term=well-being accessed on 25 May 2013

Railton, P. 1986. Facts and Values. Philosophical Topics, 14.2

Railton, P. Unpublished. Subjective Well-Being as Information Guidance. http://profron.net/happiness/files/readings/Railton_SubjectiveWellBeing.pdf

Rawls, J. 1972. A Theory of Justice. Oxford: Clarendon Press.

Rodogno R. 2008. On the Importance of Well-Being. Ethic Theory Moral Prac 11: 197-212 
Rosati, C.S. 2008. Objectivism and Relational Good. Social Philosophy and Policy, 25: 414-349

Russell, D. 2012. Happiness for Humans. Oxford: Oxford University Press

Seligman M (2011) Flourish: A Visionary New Understanding of Happiness and Well-being. Free Press, New York

Sen, A. 1985. Well-being, Agency and Freedom: The Dewey Lectures 1984. Journal of Philosophy, 82(4): 169-221.

Sen, A 1987. The Standard of Living. In Sen, Muellbauer, Kanbur, Hart, and Williams, The Standard of Living: The Tanner Lectures on Human Values, Cambridge: Cambridge University Press.

Sen, A. 1992. Inequality Re-examined, Oxford: Clarendon Press.

Sen, A. 1993. Capability and Well-being. In Nussbaum and Sen (eds.), The Quality of Life, Oxford:

Clarendon Press, pp. 30-53

Sen AK (1999) Development as Freedom. Knopf, New York

Sidgwick, H. 1907. The Methods of Ethics (Seventh Edition). London: Macmillan

Skorupski, J. 1999. Ethical Explorations. Oxford: Oxford University Press

Stiglitz, J.E., Sen, A., Fitoussi, J-P. 2010. Mismesuring Our Lives: Why GDP doesn't add up. New York: The New Press

Sumner, L. W. 1996. Welfare, Happiness, and Ethics. New York: Oxford University Press

Tiberius, V. 2008. The Reflective Life: Living Wisely With Our Limits. New York: Oxford University Press

Tiberius, V., Plakias, A. 2010. Well-Being. In Doris J.M. (ed.), The Moral Psychology Handbook. New York: Oxford University Press 